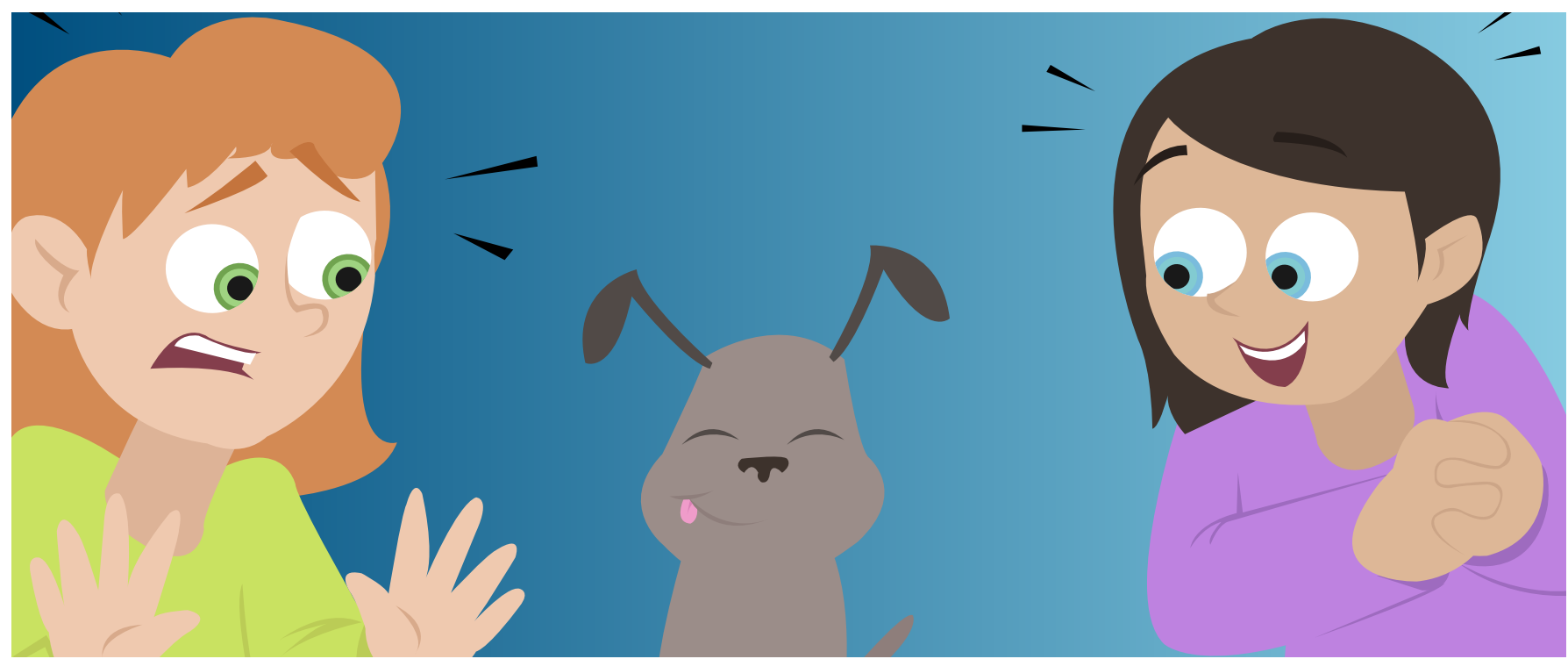

\title{
HOW DO EMOTIONS WORK?
}

\section{Ryan Smith*, Anna Alkozei and William D. S. Killgore}

Department of Psychiatry, University of Arizona, Tucson, AZ, United States

\section{REVIEWED BY: \\ LUANA \\ AGE: 11}

\section{EMOTIONS}

Feelings like sadness and anger that people have in response to different thoughts and situations. Sometimes people can also feel more than one emotion at the same time (like feeling both excited and scared to ride a roller coaster).
Have you ever felt happy, sad, angry, or afraid? How about jealous, ashamed, or embarrassed? Almost everybody has these different emotions from time to time, and they can have a big effect on the way people think and act. Because emotions have such a big effect on people's lives, scientists have spent a lot of time trying to understand how they work. In this paper, we will talk about how emotions work. First, we will talk about what causes emotions. Then, we will talk about what happens during an emotion, and how we figure out what emotions we are feeling. Last, we will talk about how we can change our emotions if we are feeling bad and want to feel better.

\section{WHAT CAUSES EMOTIONS?}

Try to remember the last time you felt scared. Do you remember what you were thinking? Scientists have discovered that our emotions are often caused by our thoughts [1]. This means two people could be in the same situation, but they might feel different emotions because they have different thoughts (see Figure 1). Maybe you have noticed this with your own friends and family. For example, imagine two people were both at a neighbor's house and this neighbor had a dog. One person might think, "This dog could hurt me!" and feel scared. This might happen if that person never had a pet dog before. The 


\section{FIGURE 1}

A person can have different thoughts about the same situation. Different thoughts can then lead to different kinds of changes in (1) what your body is doing, (2) what you pay attention to and think about, and (3) how you want to act. When you notice these changes, you can use them to figure out what emotion you are feeling.

\section{CONTROL}

Having control means that you are able to change something if you do not like it. It also means that you are able to keep something the same if you do like it.

\section{COPE}

To cope with something means to find a way to live with (or adjust to) a change in your life without feeling too bad for too long.

\section{Situation: Another kid says something mean to you at school.}

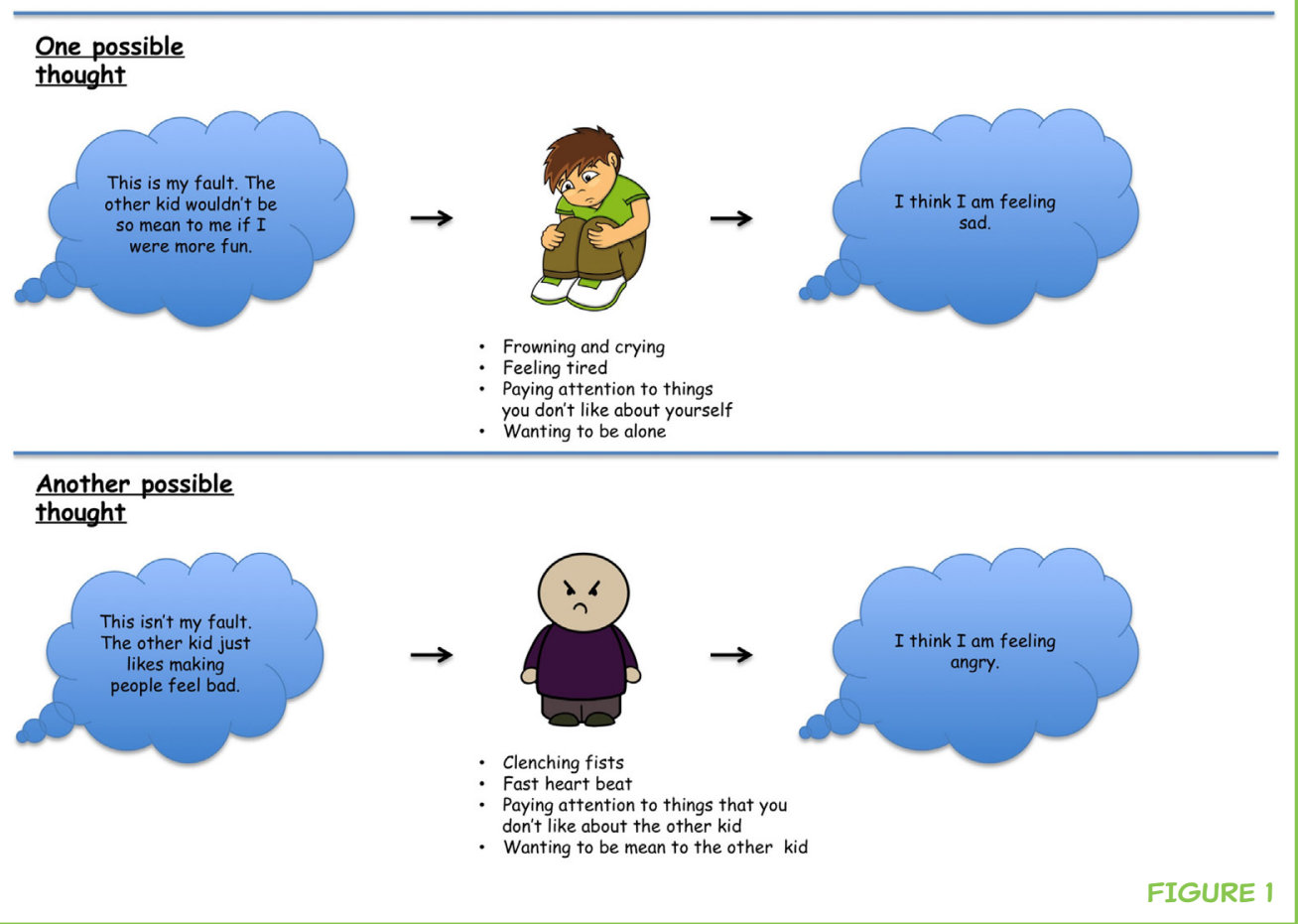

other person might instead think, "Oh, what a cute dog!" and feel happy. This might happen if that person grew up having dogs as pets. This shows how, if two people have had different experiences, they might have different thoughts and emotions in the same situation.

Scientists have found that certain kinds of thoughts often lead to certain emotions. For example, when someone thinks, "I am in danger," that person would probably feel fear. Or, when someone thinks, "I just got what I wanted," that person would probably feel happy. Or, when someone thinks, "I just lost something I care about," that person would probably feel sad. Last, when someone thinks, "My friend just treated me unfairly," that person would probably feel angry.

Scientists have discovered that the thoughts that cause emotions usually answer questions like these:

(1) Is what happened unexpected?

(2) Is what happened enjoyable?

(3) Is what happened going to make it easier or harder for me to get what I want?

(4) Can I control what happens next?

(5) Will I be able to cope with what happened?

(6) Does what happened match with what I think is right and wrong?

(7) Is what happened my fault or someone else's? 
UNCONSCIOUS PROCESSES

Things that your brain does without you knowing about it.

\section{EMOTIONAL REACTION}

The changes that automatically happen during an emotion (like changes in what your body is doing, changes in your thoughts, and changes in how you want to act).

When something happens, you will feel different emotions depending on how your mind answers these different questions. For example, if your bike just broke, you'd probably feel sadder if you didn't think you could do anything to fix it (meaning you don't think you have control). Or, if your best friend just moved away, you'd probably feel less sad about it if you also believed that you'd be able to cope and make new friends. Or, if you think it is wrong not to share, then you'd probably get angry with someone when he or she doesn't share things.

But have you ever felt an emotion and didn't know why? Sometimes people feel emotions even though they don't notice any thoughts related to those emotions. This can be hard to understand. However, scientists have found that sometimes your brain can trigger an emotion unconsciously. This means that your brain might notice something in your situation and trigger an emotional reaction, all without you even noticing it. In fact, scientists have found that our brains do lots of things that we don't notice. These are called "unconscious processes." For example, even though you don't notice it, your brain is controlling many things in your body right now, such as what your heart and stomach are doing. The next time you are feeling an emotion and don't know why, try to pay attention to what's happening in your current situation and ask yourself the seven different questions stated earlier. This might help you figure out why you are feeling the way you do.

\section{WHAT HAPPENS DURING AN EMOTION?}

When an emotion is triggered, what actually happens? Scientists have learned that an "emotional reaction" actually has many different parts [2]. One part of an emotional reaction is that the brain changes what's happening in the body. For example, when you are afraid or angry, you might feel your heart start to pound and your lungs might start breathing faster. Or, when you are sad, you might get tears in your eyes. Emotions can also cause some muscles in your body to move automatically. For example, during happiness you might smile, your voice might sound more excited, and you might stand up a bit taller-and you might not even notice you're doing these things.

Another part of an emotional reaction is that you start to think differently. For example, scientists have found that when people are sad they usually think of sad memories, but when people are happy they usually think of happy memories. As another example, when people are scared they usually start looking for other dangers in their surroundings, and they are more likely to have thoughts about other scary things. On the other hand, when people are happy, they usually notice more things that they like as they go through the day.

The last part of an emotional reaction is that you start to want to behave differently than you usually behave. For example, if you are angry, you might want 
to yell or fight with someone. Or, if you are scared, you might feel a strong desire to run away. Or, if you are sad, you may just want to stay home alone in your room and not talk to anyone.

\section{HOW DO YOU FIGURE OUT WHAT EMOTION YOU ARE FEELING?}

After we have emotional reactions, we usually also want to understand them. Have you ever been unsure about what emotion you were feeling? Sometimes our feelings can be confusing, and it can take effort to understand them. One reason for this is that the same type of emotion can sometimes feel different in different situations. For example, feeling afraid to give a speech in front of your class can feel different than feeling afraid of a lion. Another reason that feelings can be confusing is that different types of emotions can sometimes feel similar. For example, both anger and fear can make you shaky and make your heart beat faster.

So when you notice you are having an emotional reaction, you still have to figure out which emotion it is [3]. For example, you might notice that your heart is racing, that there is a lion in front of you, and that you have a strong desire to run away. After you think about different emotions you might be feeling, you could then decide that "fear" is your best guess. In other words, you might have the thought that "I'm probably feeling fear right now, because I believe this lion could hurt me." Although, with a scary situation like this, you might not even realize you are afraid until after you run away and have a moment to think about it. Scientists have found that some people find it more difficult than others to figure out what emotion they are feeling. People who have trouble understanding their emotions also have more trouble making themselves feel better.

It is important to pay attention to your emotions and to practice figuring out what you are feeling. This will help you to solve problems and to feel better faster when you are feeling bad. It also helps to ask yourself what you have learned from times when you've felt sad, or scared, or angry, and how you would handle similar situations if they happened again.

\section{CAN UNDERSTANDING HOW EMOTIONS WORK HELP YOU?}

One good reason to understand emotions is that it can help you figure out the best way to respond to them. To figure out how to respond, it is important to first decide if your emotions match the current situation. Emotional reactions can be helpful when they happen in the right situations. For example, if you feel scared of a snake, your emotion of fear will help you stay away from snakes 


\section{REAPPRAISAL}

One good skill for dealing with unhelpful emotions. To do this, you first notice what thoughts you are having in a situation. Then you try to find another way to think about the situation that might make you feel better.

\section{APPROACHING YOUR FEAR}

A good skill for dealing with unhelpful fear. To do this, you first decide that it is ok to be feeling fear. Then you decide to still do what you are afraid of, even though the fear is still there. This can help you learn to be less scared in the future. and avoid getting bitten. Or, if you get angry when someone does something mean to you, your anger can let that person know not to be mean anymore. Or, if your family and friends notice that you are sad after a friend moves away, your sadness can help them see that you need their love and support.

However, sometimes these same emotions can be unhelpful if they happen in the wrong situations. For example, if you get angry with a friend because he hurt you by accident, then this might just make your friendship worse. Or, if you are so scared of taking a test that you stay home from school, then this might stop you from getting a good grade in that class. Or, if you are sad for too long after a friend moves away, then this might make it harder for you to make new friends.

If an emotion is helpful, you can listen to what it is telling you to do. But what should you do if an emotion is unhelpful? Scientists have found that there are some good skills you can practice, which can help you deal with unhelpful emotions. One skill-called "reappraisal"-involves trying to change your thoughts [4]. For example, if you are scared to go to school to take a test, then you could try to find another way to think about the test that is less scary. For instance, you might think, "Well, I passed all of the other tests I have had to take, so this one will probably be ok too." Or, if you were angry with a friend because he hurt you by accident, you might try to think, "It was just bad luck-I know he didn't mean to hurt me." If you change your thoughts about a situation, this can sometimes help change an unhelpful emotion as well.

If you are feeling fear, and it is unhelpful in the current situation, then another useful skill is called "approaching your fear" [5]. To understand how this works, first remember that, when people are scared of something, they usually want to do everything they can to avoid it. For example, you might not want to go to school because you are scared of giving a class presentation. The problem is that when you avoid situations like this (situations that are not actually dangerous), then you can never learn not to be scared of them anymore. Instead, if you force yourself to give many different class presentations, then eventually you'll probably stop feeling as scared of them (see Figure 2). Scientists have found that approaching your fears (this means doing what you are scared of) is one of the best ways to make your fears go away.

If you are feeling angry or sad, other things that can help are exercise and activity. For example, when people are angry, they usually want to yell or say mean things. But going for a run instead often helps people calm down and think more clearly, and it also puts them in a more positive mood. As another example, when people are sad, they often just want to stay home in their rooms alone and think about their problems. However, this can sometimes just make them feel worse (see Figure 3). When you are sad, even if you don't feel like it, it can actually help a lot to go outside and do something active. For example, you could go spend time with a friend or go for a walk through a park. 


\section{FIGURE 2}

In the example on the top, you decide to stay home from school because you are scared to give a class presentation. In the future, you are always too scared to give class presentations. In the example on the bottom, you are also scared to give a class presentation, but you decide to do it anyway. In the future, you become less scared of giving class presentations. These examples show how "approaching your fears" can help you learn to be less scared in the future.

\section{FIGURE 3}

In the example on the top, you decide to stay home alone because you are sad you didn't get invited to a party. You keep thinking about why you didn't get invited to the party, and you still feel sad many hours later. In the example on the bottom, you are also sad you didn't get invited to a party, but you decide to go outside and do something else fun instead. You stop worrying so much about the party, and you feel much happier a few hours later. These examples show how going outside and doing something active can help you feel better when you are sad. Even if you don't feel like it, you will often feel better faster if you do this. Doing something active can also help if you are feeling angry and you want to calm down before you accidently yell or do something mean.

\section{Situation: Feeling scared to give a class presentation.}

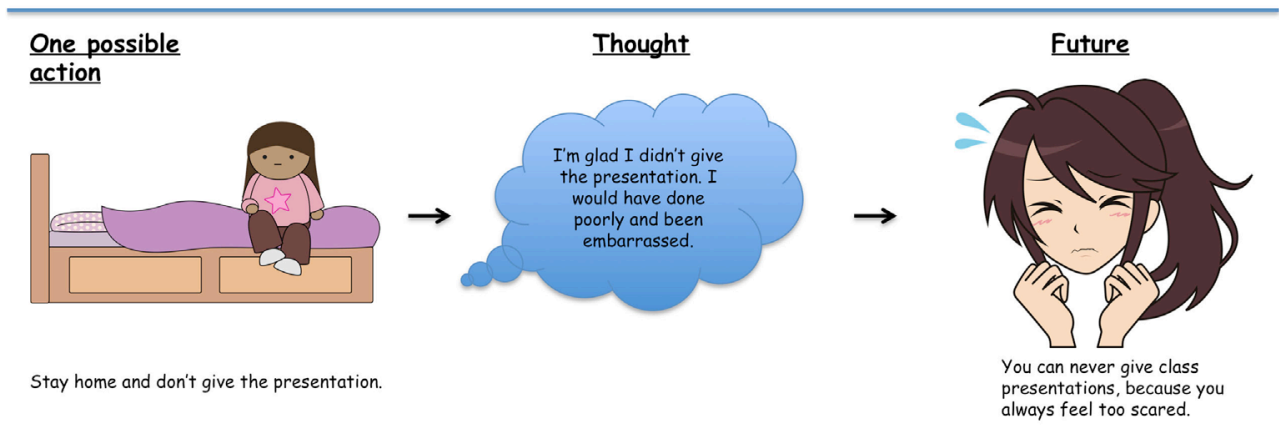

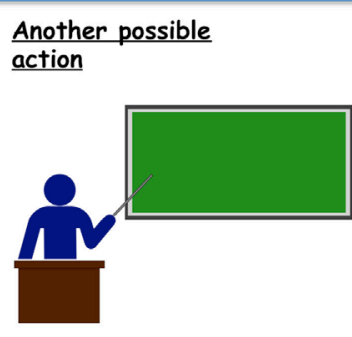

Give the presentation anyway
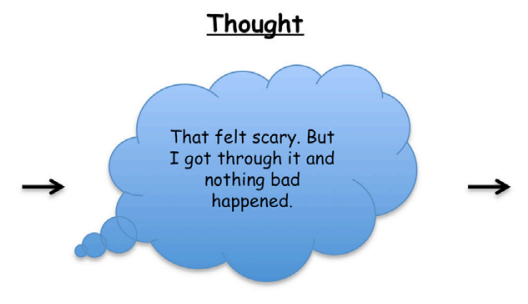
feel as scared anymore.

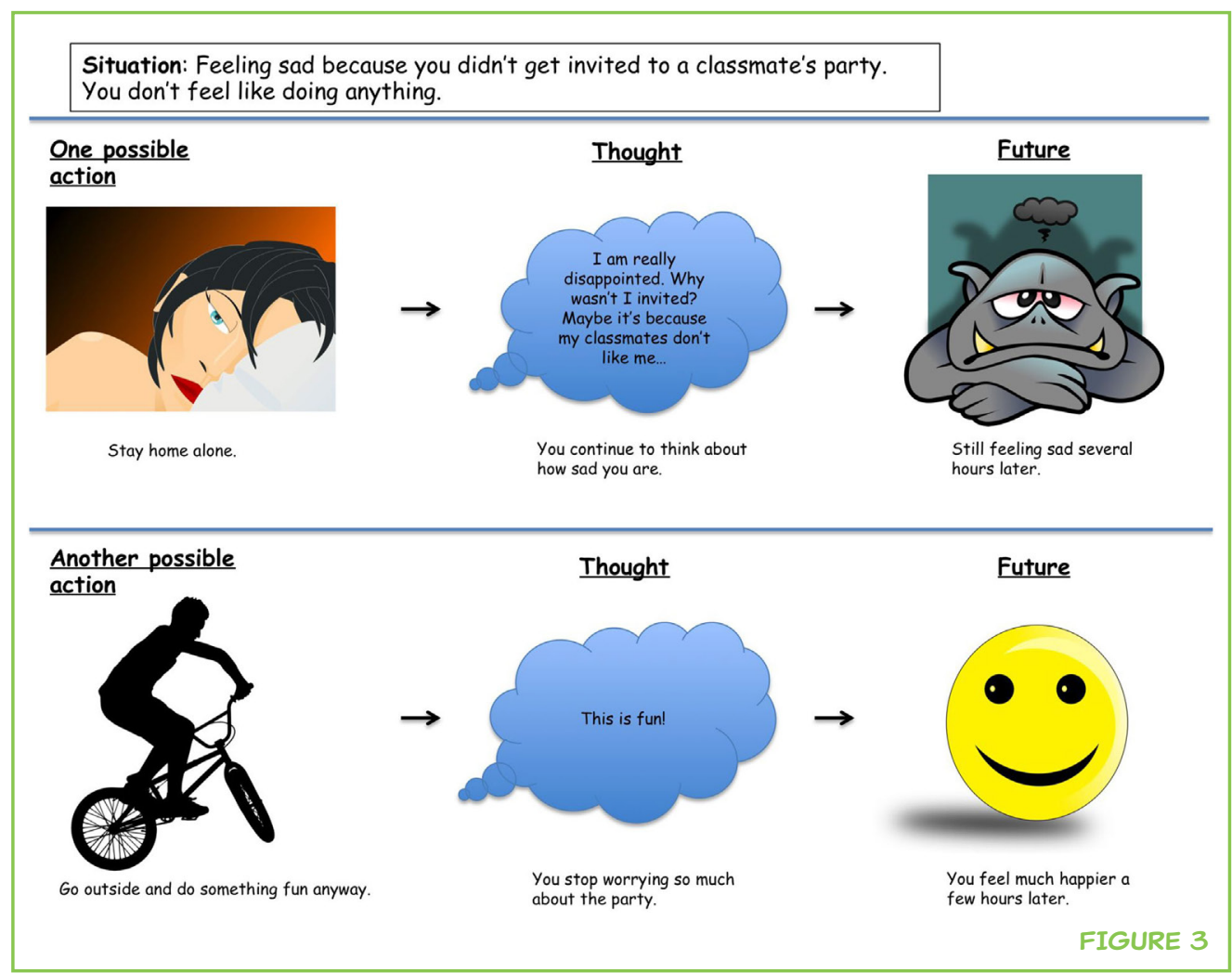

One other reason that understanding emotions can be good is it can help you understand other people. Perhaps you have seen people get angry or sad in a situation, but you couldn't figure out why they felt that way. After reading 
this paper, you know that these people probably think of this situation in a different way than you do. The reason they think of the situation differently is probably because they have also had different life experiences than you have had. In general, if you spend a little time trying to figure out what a person's thoughts might be, and what past experiences that person has had, this will probably also help you understand why that person feels the way they do.

\section{SUMMARY}

In this paper, you have learned many things about emotions. First, your emotional reactions are usually caused by your thoughts; however, sometimes your brain can also trigger an emotional reaction unconsciously (meaning that you may not understand why that emotional reaction is happening). Second, your emotional reactions involve changes in (1) what your body is doing, (2) what you pay attention to and think about, and (3) how you want to act. Third, after you have an emotional reaction, it is important to pay attention to it and to try your best to figure out which emotions you are feeling and why. Finally, you have learned that it is important to know how emotions work because it can help you respond to your emotions in healthier ways.

\section{REFERENCES}

1. Scherer K. 2009. The dynamic architecture of emotion: evidence for the component process model. Cogn. Emot. 23:1307-51. doi:10.1080/02699930902928969

2. Smith, R., Killgore, W. D. S., and Lane, R. D. 2017. The structure of emotional experience and its relation to trait emotional awareness: a theoretical review. Emotion. doi:10.1037/emo0000376

3. Barrett, L. 2017. How Emotions are Made: The Secret Life of the Brain. New York: Houghton Mifflin Harcourt.

4. Buhle, J., Silvers, J., Wager, T., Lopez, R., Onyemekwu, C., Kober, H., et al. 2014. Cognitive reappraisal of emotion: a meta-analysis of human neuroimaging studies. Cereb. Cortex. 24:2981-90. doi:10.1093/cercor/bht154

5. Barlow, D., Frachione, T., Fairholme, C., Ellard, K., Boisseau, C., Allen, L., et al. 2011. Unified Protocol for Transdiagnostic Treatment of Emotional Disorders Therapist Guide. New York: Oxford University Press.

SUBMITTED: 30 October 2017; ACCEPTED: 06 December 2017; PUBLISHED ONLINE: 22 December 2017.

EDITED BY: Rossana De Lorenzi, Associazione Adamas Scienza, Italy

CITATION: Smith R, Alkozei A and Killgore WDS (2017) How Do Emotions Work? Front. Young Minds 5:69. doi:10.3389/frym.2017.00069 
CONFLICT OF INTEREST STATEMENT: The authors declare that the research was conducted in the absence of any commercial or financial relationships that could be construed as a potential conflict of interest.

COPYRIGHT (C) 2017 Smith, Alkozei and Killgore. This is an open-access article distributed under the terms of the Creative Commons Attribution License (CC BY). The use, distribution or reproduction in other forums is permitted, provided the original author(s) or licensor are credited and that the original publication in this journal is cited, in accordance with accepted academic practice. No use, distribution or reproduction is permitted which does not comply with these terms.

\section{REVIEWED BY}

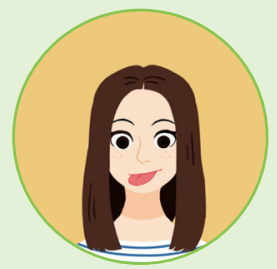

\section{LUANA, AGE: 11}

I was born in USA and lived in Canada for 5 years. That is why I can speak English so well. Both my parents are scientists (microbiologists), so I think that is why I always loved science.

\section{AUTHORS}

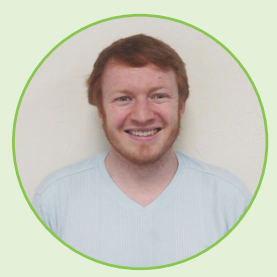

\section{RYAN SMITH}

I am a researcher at the University of Arizona. I have a PhD in Psychology and a background in research on emotions and the brain. I am interested in trying to understand how the brain generates emotions, and how this process can break down in people with depression and anxiety. In my free time, I like to go hiking, skiing, and traveling to new places. ${ }^{*}$ rsmith@ psychiatry.arizona.edu

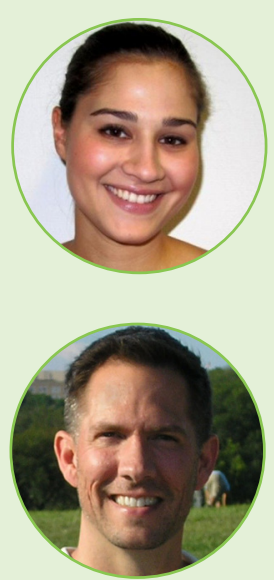

\section{ANNA ALKOZEI}

I work as a researcher at the University of Arizona. I am originally from Germany, but completed my PhD in Psychology in the United Kingdom. I am interested in finding out what adults and children can do to live happier and healthier lives. I love to do yoga, ride my bike, and play with my cat Lily.

\section{WILLIAM D. S. KILLGORE}

I am a professor at the University of Arizona and Harvard Medical School and am also an Officer in the U.S. Army Reserve. I have a PhD in Clinical Psychology and a background in sleep and performance research. In my lab, we study how different kinds of stresses and injuries affect the brain and how we can improve people's mental performance. We study ways to help people think faster, feel better, and heal from traumatic experiences. Our work uses the most advanced techniques in brain imaging, brain wave monitoring, sleep monitoring, mental testing, internet training, and other high-tech tools to study how the brain works and how to help people perform better and live healthier lives. 